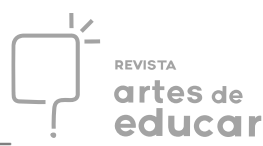

\title{
CORPO E DANÇA: ANGEL VIANNA E A MANUTENÇÃO DA SENSIBILIDADE
}

\author{
Márcia Feijó de Araújo
}

\begin{abstract}
Resumo: A pedagogia corporal criada e desenvolvida por Angel Vianna é o centro desta reflexão sobre o papel da sensibilidade na formação do indivíduo em sociedade. Coloca-se em debate uma pedagogia corporal não excludente, como são os princípios do trabalho artístico e pedagógico de Angel Vianna. Sua metodologia procura, por meio de práticas educativas de sensibilização, formas de colaborar com a capacidade humana de se desenvolver e se comunicar. A percepção de si mesmo e do outro é elemento fundamental desse processo educativo proposto por Angel Vianna, e dialoga com a perspectiva teórica de Fayga Ostrower, que valoriza o papel da Arte para recuperar valores humanos primordiais. Em sua metodologia, Angel estabelece uma conduta de aceitação de todos, valorizando a diversidade humana, sem espaço para julgamentos ou padronizações.
\end{abstract}

Palavras-chave: Dança; Corpo; Sensibilidade; Metodologia.

\section{BODY AND DANCE: ANGEL VIANNA AND THE MAINTENANCE OF SENSITIVITY}

\begin{abstract}
The corporeal pedagogy created and developed by Angel Vianna is the center of this reflection about the role of sensitivity in the formation of individuals in society. We debate a non-excluding body pedagogy, as proposed by the artistic and educative work of Angel Vianna. This methodology searches, through practices to raise awareness, ways to collaborate with the human capacity of developing and communicating. The perception of the Self and the Other is a fundamental element of this educative process proposed by Angel Vianna, and dialogues with the theoretical perspective of Fayga Ostrower, who values the role of Art to recuperate primordial human values. In her methodology, Angel stablishes a conduct of acceptance, valuing the human diversity, without room for judgment or standardization.
\end{abstract}

Keywords: Dance; Body; Sensitivity; Methodology

\footnotetext{
"Há uma necessidade de uma formação adequada para um aprendizado claro e transdisciplinar, integrando não só o trabalho científico e o trabalho físico, mas também o desenvolvimento do ser humano através da criatividade, comunicação e socialização. (ANGEL VIANNA)
} 


\section{Angel Vianna: uma matriz pedagógica de sensibilização}

Angel Vianna, notável artista, bailarina, coreógrafa e educadora corporal que ao longo de sua vida vem formando muitas e muitas gerações, aprimorou um olhar atento ao mundo, às coisas e, principalmente, às pessoas, pelas quais sempre afirmou ser fascinada. As expressões, os movimentos e as infinitas possibilidades do corpo humano, são os motivos pelos quais, ao longo de muitos anos de atividade profissional, desenvolveu e lapidou um reconhecido trabalho de potencialização e sensibilização do corpo.

Suas pesquisas sobre corpo e movimento se desenvolveram ao lado do parceiro de vida Klauss Vianna ${ }^{1}$, desde a abertura de sua primeira escola de dança, o Ballet Klauss Vianna (1959 - 1961), em Belo Horizonte, Minas Gerais. Essa escola foi o ponto de partida das pesquisas corporais que ambos desenvolveram ao longo de seus caminhos. Passaram por Salvador, como professores convidados na Universidade Federal da Bahia (UFBA) entre 1962 e 1964, e chegaram ao Rio de Janeiro em 1965, onde Angel Vianna trabalha e reside até hoje. Juntamente com a amiga e bailarina Tereza d'Aquino, os Vianna abriram sua segunda escola, dessa vez no Rio de Janeiro, na Rua Góes Monteiro, em Botafogo: o Centro de Pesquisa Corporal Arte e Educação (1975 - 1982). Em 1983, Angel inaugura junto com seu filho Rainer Vianna $^{2}$ e sua nora Neide Neves uma nova escola, localizada na Rua Jornalista Orlando Dantas $\mathrm{n}^{\mathrm{o}}$ 2, também em Botafogo: o Espaço Novo - Centro de Estudos do Movimento e Artes, atualmente a Escola e Faculdade de Dança Angel Vianna (EFAV).

Desde o início de sua carreira, Angel demonstra sua vocação para educadora. Sua sensibilidade e o seu grande apreço pelo ser humano a impulsionam a abrir suas próprias escolas, para que ela mesma pudesse criar, experimentar e desenvolver sua percepção de que o corpo é mais do que um instrumento para se viver: o corpo é para ser sentido plenamente.

Apesar de ter partilhado todo o desenvolvimento técnico sobre as expressões e potencialidades do corpo ao lado de Klauss Vianna, Angel foi responsável por experimentar e desenvolver didaticamente essa pesquisa em turmas regulares de dança e expressão corporal em sua escola. Para embasar esse processo educativo e investigativo de forma abrangente, foi necessário criar, gradualmente, uma metodologia que atendesse aos princípios de respeito e valorização da diversidade de todos os que participavam de suas aulas. Seu trabalho propõe, para cada indivíduo, infinitas possibilidades de percepção e uso do próprio corpo, respeitando a singularidade de cada um. Inicialmente, Angel Vianna denominou seu trabalho com o termo 
Expressão Corporal, mas posteriormente, adotou o nome de Conscientização do Movimento e Jogos Corporais. Com o passar do tempo e aprofundamento em suas pesquisas e descobertas, percebeu que o termo "Expressão Corporal” fora banalizado. Assim, conforme destaca Ramos:

Angel Vianna passou a usar outro nome para designar seu trabalho, uma vez que o termo "expressão corporal" não daria a dimensão exata de sua extensão. Expressar, diz ela, é um ato inerente a qualquer ser humano, do nascimento à morte. Em se tratando de atores e bailarinos, pessoas que usam a expressão como veículo da arte, era necessário definir esse trabalho de modo mais claro e objetivo. O corpo tem uma memória muito aguçada, muito presente, registra tudo que acontece na vida do indivíduo, e esse registro permanece para sempre. (...) Por isso a prática foi chamada de Conscientização do Movimento, por ser o modo pelo qual ela trabalha a expressividade. (RAMOS, 2007, p.24)

A Conscientização do Movimento proposta por Angel Vianna visa estimular e resguardar a sensibilidade para a autopercepção do corpo em ação. Dessa maneira - atenta, sensível e ativa -, a pessoa ocupa plenamente seu espaço no mundo, em diálogo vívido com a cultura. Por meio de exercícios e estudos detalhados e paulatinos sobre o reconhecimento profundo de nossa estrutura esquelética, de nossas dobras (articulações), do nosso invólucro (pele), pratica-se o refinamento dos sentidos e da pesquisa do movimento próprio.

Segundo Angel Vianna, o corpo contém todos os registros dos fatos vividos, pois estes são armazenados e inscritos em nossa complexidade corpórea. Desse modo, sua metodologia nos propicia uma leitura particular a respeito das nossas sensações, de nossa memória corporal; e também contribui para a aquisição de um estado sensível, alerta e cuidadoso de si mesmo, criando novas possibilidades de expressão e diálogo com o outro e com o mundo ao redor. Essa abordagem estuda e pensa o corpo em ação, renovando experimentações a partir de cada segmento corporal pesquisado, resultando numa percepção global minuciosa e equilibrada.

Trata-se de uma abordagem educacional que se concretiza em aulas regulares para qualquer tipo de pessoa que deseje investir em autoconhecimento, equilíbrio, expressão e expansão da criatividade. Dentre os muitos resultados desse aprofundamento num estudo sobre si mesmo, pode-se citar a autorregulação do tônus muscular, da organização postural, do equilíbrio e facilitação das inúmeras possibilidades de movimento, sem sobrecargas ou desgastes desnecessários.

Com espreguiçamentos, bocejos e alongamentos que liberam as tensões acumuladas no cotidiano, iniciam-se as aulas de profunda pesquisa na estrutura corporal. Por 
meio de um comando firme e objetivo ocorre, gradativamente, um relaxamento atento, mas não abandonado do corpo, onde a pessoa, deitada no chão, realiza uma verificação minuciosa de cada segmento corporal. A aula vai se desenvolvendo a partir dessas informações iniciais e das condições pessoais naquele momento. Algumas vezes são constatados certos incômodos e desconfortos corporais, resultantes de limitações de movimentos e tensões em algumas partes. A disponibilidade de concentração mental e observação de si mesmo para a realização desse reconhecimento detalhado do próprio corpo é fundamental nessa abordagem, em que sensações físicas e pensamento atento se integram, refinando a percepção de si mesmo.

As aulas são realizadas com roupas confortáveis e flexíveis, sala própria para que possam acontecer movimentos amplos, e para que haja a possibilidade de usar o chão com liberdade para deitar-se e pesquisar as variações do peso natural de cada corpo e seus apoios. Com uma ampla gama de exercícios e propostas de pesquisa do corpo em sua potência perceptiva, enfatiza-se o reconhecimento da nossa estrutura interna (esquema musculoesquelético), da ocupação espacial de cada segmento ósseo, da projeção e alinhamento dos planos do corpo no espaço e do comportamento do nosso "recheio", como nos diz Angel, referindo-se a tudo o que há no espaço entre os ossos e a pele.

Passo a passo, o aluno se apropria de uma organização corporal mais integrada, graças ao refinamento sensorial adquirido e à experiência musculoesquelética. Aprende também a aplicar um tônus adequado para seus movimentos, melhorando, assim, seu funcionamento estrutural, inclusive no que diz respeito ao próprio ato involuntário da respiração, pois um dos aprendizados fundamentais envolve saber liberar o centro diafragmático de tensões desnecessárias. Alguns objetos, tais como caules de bambu, bolinhas de tênis e saquinhos de areia, tornam-se recursos didáticos lúdicos e eficientes nas abordagens mais profundas de percepção dos espaços internos e dos micromovimentos corporais.

A pele é um dos elementos fundamentais segundo o método de Angel Vianna. É através dela que se faz a troca de informações entre as percepções internas/externas de cada pessoa. Ela é a ponte do relacionamento consigo próprio e também com o outro e o mundo. Por envolver todo o corpo, ela detém as informações que regulam as tensões, mantendo o equilíbrio do tônus, necessário à motricidade e facilitador da expressão. São utilizados vários estímulos ao longo da prática para sensibilizar, relaxar, revigorar e informar a pele, tais como toques suaves e precisos, palpação, massagens, percussão óssea etc. 
A fim de averiguar e harmonizar as percepções e conquistas trabalhadas em aula, a dança entra como fator fundamental para apreensão dos conhecimentos adquiridos. A dança livre e própria de cada indivíduo, sem prévia coreografia, sem modelo a ser seguido, torna-se ponto fundamental e o auge da experiência do movimento expressivo, da criatividade e da autonomia. Trata-se de uma dança própria e pessoal de cada um, pautada nos limites e na espontaneidade, autênticos de cada corpo. Através dessa dança, o conhecimento adquirido se revela em gestos e movimentos reorganizados, coerentes com seus corpos, que surgem a partir do fluxo natural das pulsões dos desejos internos, dos intentos criativos, armazenando mais e mais experiências e suprindo de satisfação um corpo nascido para mover-se e expressar-se plenamente.

Trabalhos individuais, em duplas e grupos são inúmeros, contendo múltiplas possibilidades de expressão na dança e nos jogos corporais propostos por Angel Vianna. Através do contato com um caule de bambu, por exemplo, pode-se experimentar o espaço e sua existência nele, através da inércia ou do movimento, constatando aspectos como a gravidade atua sobre cada parte do corpo, as texturas de contato, a amplitude articular e o alinhamento ósseo. Em atividades coletivas, geralmente na realização dos jogos corporais da metodologia de Angel Vianna, a observação atenta das soluções corporais do outro enriquece a criatividade, a compreensão dos modos de existir e o acervo de movimentos possíveis em diferentes situações. Esse processo educativo do corpo necessita de dedicação pessoal, foco e um longo tempo para que cada um, em cada etapa de sua vida, possa elaborar um estado de percepção apurado sobre si mesmo, com domínio e autonomia.

É através dessa abordagem sensível, eficiente, profunda e libertadora, que Angel Vianna vem, ao longo do tempo, trabalhando na revelação e na manutenção da sensibilidade e do melhor uso corporal possível para todos, irrestritamente, sejam crianças, jovens, adultos, idosos, pessoas com necessidades especiais, artistas e profissionais de todas as áreas. A formação na Escola e Faculdade Angel Vianna contém essa matriz pedagógica em todos os seus currículos: Cursos Livres, Cursos Técnicos, Graduações e Pós-Graduações.

\section{Sensibilidade, consciência e criatividade}

Professores de Artes em geral se debruçaram em conseguir formas de preservar o potencial humano de ser sensível e criativo ao longo da vida. A proposta de recuperação das 
potencialidades humanas que se convertem em necessidades existenciais, nas palavras de Fayga Ostrower (2012), consiste em desenvolver a percepção de si mesmo dentro do agir, sendo isso um aspecto de extrema importância, que distingue a criatividade humana:

(...) tentamos recuperar certos valores humanísticos, fornecer alguns elementos para que se enfrente melhor uma época como a nossa, em que dos sistemas e dos processos dirigidos de massificação só vemos resultar um condicionamento muito grande para os indivíduos, um aviltamento e um esmagamento do seu real potencial criador. (OSTROWER, 2012, p.7).

Para Fayga Ostrower assim como para Angel Vianna, a criatividade depende da sensibilidade. Criar é uma necessidade. Fayga reitera que a percepção de si mesmo na hora de agir corresponderia aos modos pelos quais os indivíduos dirigiriam sua força física e intencional em suas expressões, e assim, o ato criador realizado através do próprio corpo não existiria antes ou fora do ato intencional:

(...) não haveria condição, fora da intencionalidade, de se avaliar situações novas ou buscar novas coerências. Em toda criação humana, revelam-se certos critérios que foram elaborados pelo indivíduo através de escolhas e alternativas (OSTROWER, 2012, p.11).

Cada indivíduo possui em seu acervo de expressões e reações pessoais a memória das escolhas e alternativas vivenciadas ao longo de sua vida. Mas, a respeito das escolhas e alternativas num mundo cada vez menos empático e tolerante com os processos e ritmos individuais, os critérios para desenvolvimento de qualquer proposta de trabalho artístico devem ser analisados e aplicados levando-se em consideração as múltiplas trajetórias de formação de cada sujeito e sua história particular inscrita em seu corpo.

Assim como Fayga, também Angel preocupa-se com o processo de escolhas sensíveis e melhores alternativas no cotidiano dos sujeitos. Ambas também determinaram, em suas abordagens, distintas formas de ressignificar a importância da consciência e da criatividade na ação dos corpos, na utilização plena de suas capacidades no exercício de suas funções cotidianas e de suas expressões próprias. Sempre em contraponto às massificações produzidas pela lógica do consumo nas sociedades neoliberais.

Os debates sobre o papel de destaque dado ao corpo e suas representações na cultura do "corpo perfeito" tem influenciado sobremaneira a formação de crianças e jovens, implicando 
em graves problemas sociais, além da disseminação permanente de todo tipo de preconceito. A incidência dessas distorcidas concepções atinge cidadãos de todas as classes sociais causando desigualdade e segregação. As duas educadoras e artistas aqui citadas desejaram evidenciar a potência singular das expressões singulares de cada corpo, cada história, cada processo criativo. Em suas propostas, chamam atenção e se preocupam com uma frequente falta de criatividade, um estado alienado e uma apatia social que, com relevância, têm sido objeto de estudo nos campos da Educação, da Arte e das Ciências Humanas em geral. Essas pautas buscam um redirecionamento das percepções individuais e coletivas, além de cuidados com a diversidade.

As mulheres aqui citadas, Angel e Fayga, em suas ações e consequentes legados, apontam para a necessidade premente do autoconhecimento e da percepção do potencial criativo inerente ao ser humano. Enquanto a metodologia de Angel Vianna é praticada artística e pedagogicamente por todos os corpos, todas as pessoas. Estabelece intencionalmente uma conduta de aceitação de todos, valorizando a diversidade humana, sem espaço para julgamentos ou padronizações. Já para Fayga, qualquer ato criativo, de qualquer pessoa, estaria dentro de uma intencionalidade humana, nem sempre consciente, mas estruturada, revelada e decodificada pela sensibilidade.

Com isso, pode-se conjecturar que a manutenção da sensibilidade é o cerne da pesquisa de ambas. Fayga apresenta o ser humano como Ser consciente-sensível-cultural (2012, p. 11) e defende que é na integração desses três aspectos que se baseiam os comportamentos criativos das pessoas. O ser consciente-sensível, ao conscientizar-se de sua existência individual, conscientiza-se sobre sua existência social.

A premência de abordagens educacionais que contemplam respeito, aquisição de autonomia e conscientização dos indivíduos, não só para um bom exercício de cidadania, mas também para o desenvolvimento e manutenção da criatividade humana, aponta para a potencialidade das Artes e seu ensino, em todas suas formas e linguagens. Principalmente para expressão dos sentimentos de afeto e de amor necessários para o ato de viver. O papel do ensino de Artes há muito vem exercendo importante função na sensibilização contra as várias formas de violência.

A dança, por exemplo, no sentido proposto por Rudolf Laban (1990), traz em sua prática a possibilidade de fomentar a expressão artística no âmbito da arte primária do movimento em dois sentidos: de fruir a criatividade e afetividade e de cultivar a capacidade de tomar parte na expressão coletiva das tradições corporais da história da humanidade. Para Klauss Vianna 
(1990), é por meio dos movimentos que nós nos tornamos conscientes de nós mesmos, do nosso corpo e dos estados internos que expressamos ao nos movermos.

Mas, se a dança é um modo de existir, cada um de nós possui a sua dança e o seu movimento, original, singular e diferenciado, e é a partir daí que essa dança e esse movimento evoluem para uma forma de expressão em que a busca da individualidade possa ser entendida pela coletividade humana. (VIANNA, 1990, p. 88)

Experiências criativas vividas no corpo por meio de abordagens sensíveis, que respeitem um tempo próprio, ou seja, o tempo naturalmente afinado e viável para a construção de um saber sobre nós mesmos, têm sido frequentemente suprimidas diante do imperativo da vida moderna. É exatamente para criar espaço-tempo e escuta significativos para uma formação sensível, que respeite as diferenças, expanda as formas de convivência e crie novas formas de diálogos, que propostas de manutenção da sensibilidade através das Artes tornam-se necessárias e fundamentais nos processos educacionais.

A proposta de Angel Vianna e de Fayga Ostrower na recuperação da experiência formativa por meio da sensibilidade evidencia o fato de que o processo de conscientização se desenvolve junto ao processo de promoção da espontaneidade, da criatividade, da originalidade e, portanto, é também promotora fundamental de autonomia e emancipação nos sujeitos.

Ostrower desejava acionar uma seleção latente seletiva (2012, p.10) na reeducação da integralidade do humano, lembrando que a consciência e a sensibilidade fazem parte de uma herança biológica inata desde os "homínidas", e que a cultura representa o desenvolvimento social do homem. Assim, coloca em prática seus conceitos, Ser consciente-sensível-cultural e propõe a experiência com a arte como canal potente para recuperar valores humanos primordiais, capacitando os sujeitos contra a opressão social alienante e, fundamentalmente, resguardando o processo de criação: fator de extrema realização e constante transformação humana. A percepção além de nós permite movimentos empáticos frente às expressões subjetivas, muito além das palavras. A pesquisa corporal dos Vianna também desenvolveu esse fator:

O processo de expressão corporal na mesma medida que vai desverbalizando - tornando as palavras cada vez mais sem sentido, vai ampliando a percepção visual, tátil e motora. O indivíduo vai aprender a existir em um mundo cada vez mais amplo, mais rico e mais complexo. Basta isso para alterar consideravelmente as palavras. Antes as pessoas viviam na convicção de que 
o dizível é o mais importante ou quase tudo. Depois ele percebe que o indizível é maior. (VIANNA, 1990, p)

Outro fator observado por Angel e Fayga é o tempo. A incidência do tempo no corpo é veloz e a velocidade da vida urbana moderna preocupou e causou a necessidade de criação de meios para que a sensibilidade e a consciência de si não fossem suprimidas da vida. Em um processo de conscientização, na contramão do que nos exigem as urgências da vida contemporânea, subjaz um tempo fecundo, destinado a desvelar formas expandidas do tempo presente, nos possibilitando, através da experiência, meios possíveis de superação das ameaças e dos perigos de uma vida esvaziada de significações consistentes para os sujeitos e seus pares.

A percepção deste fator fica muito clara numa aula de Angel Vianna: trata-se do tempo interno. Importante. Um tempo orgânico que nos é roubado se formos descuidados. O tempo de elaboração das expressões, dos encontros, das apreciações, da Arte. A dança, a poesia, a pintura, a escultura, a música, a literatura e tantas outras formas de expressão precisam ser contínua e abundantemente geradas. Deveria ser um fluxo natural, mas os parâmetros culturais nos conduziram a outras práticas. As educadoras e artistas aqui citadas fizeram de suas vidas uma realidade política, filosófica e histórica.

Para além da formação dos sujeitos, a necessidade da relação com a Arte encontra-se socialmente ameaçada, principalmente devido às atuais políticas públicas voltadas para a área cultural, que não apresentam oportunidade para nada que não seja sancionado por elas mesmas de antemão. Vive-se um Estado sem responsabilidade com a cultura, desinteressado em estimular a liberdade de expressões artísticas. Essa problemática torna-se evidente quando nos deparamos com índices alarmantes de violência e intolerância ligadas a qualquer diversidade, seja ela religiosa, sexual, étnico-racial, social etc. Não deveríamos viver sem práticas periódicas de manutenção e desenvolvimento da sensibilidade, da criatividade, da possibilidade de adquirirmos consciência de nós mesmos.

A consciência do movimento e a dança fazem parte de um processo educacional que desenvolve a criatividade, a comunicação e a alegria num percurso dinâmico, ao longo de toda a vida. (VIANNA, apud CALAZANS, CASTILHO; GOMES, 2003, p. 9) 
Em suma, a manutenção da sensibilidade é um trabalho contínuo. A conscientização do movimento, a dança e a expressão do corpo como potência transgressora, ousada, artística e política, são pilares do trabalho corporal e da metodologia desenvolvida por Angel Vianna, atualmente com 91 anos e à frente de sua Escola e Faculdade de Dança.

\section{REFER $\hat{E} N C I A S$}

CALAZANS, Julieta; CASTILHO, Jacyan; e GOMES, Simone (Coordenadores). Dança e Educação em Movimento, São Paulo: Cortez, 2003.

LABAN, R. Domínio do moviment $o$. São Paulo: Summus, 1978.

Dança Educativa Moderna. São Paulo: Ícone, 1990.

OSTROWER, F. Criatividade e Processos de Criação. Petrópolis, RJ: Vozes, 2012.

RAMOS, E. Angel Vianna: a pedagoga do corpo. São Paulo: Summus, 2007.

VIANNA, K.; CARVAlHO, M. A. A Dança. São Paulo: Siciliano. 1990.

\footnotetext{
i Escola e Faculdade Angel Vianna, Rio de Janeiro, RJ, Brasil. https://orcid.org/0000-0001-7002-2502 (marciafeijo@hotmail.com)

1 Belo Horizonte, 1928 - São Paulo, 1992.

2 (Belo Horizonte, 1958 - Rio de Janeiro 1995).
} 